\title{
PARENTAL APPROACHES AND MEDICATION USAGE IN CASE OF ACUTE RESPIRATORY INFECTIONS IN CHILDREN
}

${ }^{1} \mathrm{~N}$. Mchedlishvili , ${ }^{2} \mathrm{M}$. Kherkheulidze , ${ }^{3} \mathrm{E}$. Karkashadze

${ }^{1}$ Center Of Allergy and Immunology, Tbilisi, Georgia

${ }^{2}$ Tbilisi State Medical University, Tbilisi, Georgia

${ }^{3}$ Infectious Diseases, AIDS and Clinical Immunology Research Center, Tbilisi, Georgia

\section{Background and Aims}

In the country of Georgia the main problem in the management of acute respiratory infections (ARI) in children is overutilization of medications, particularly antibiotics. We studied parental approaches and medication usage in case of acute respiratory infections in children.

\section{Method}

I23 households in west part of Georgia were interviewed using specially designed questionnaires for parents. Information was obtained about demographic characteristics, child's health status, including frequency of ARI, medication usage, and primary care visits. Statistical analysis was performed using SPSS 20 software.

\section{Results}

Of 123 children, the mean age was $3.05 \pm 2.65$ years and $7 \mathrm{I}$ $(57.7 \%)$ were boys. The majority of children (44.2\%) had 3-5 episodes of ARI per year, $39.2 \%$ had $\leq 2$ episodes and $16.7 \%$ experienced $\geq 6$ respiratory infections per year Parents perceived as worrying symptoms: refusing to eat and drink in $33.7 \%$ cases, high temperature $\left(>39^{\circ} \mathrm{C}\right)$ in $28.3 \%$, apathy/somnolence in $22.3 \%$, vomiting in $12 \%$, and convulsions in $3.6 \%$. Only $3.3 \%$ of parents administered antipyretic drugs at the temperature $>38,5^{\circ} \mathrm{C}$, the majority $(79.3 \%)$ - at the temperature $>38^{\circ} \mathrm{C}$, and the rest at or below $37,5^{\circ} \mathrm{C}$. $50.4 \%$ of parents received phone consultation from private doctor, $36.8 \%$ brought their child to doctor's office/clinic and others did not contact doctor. Drugs used by respondents in children for ARI were: antipyretics in $69.0 \%$, antitussives in $24.1 \%$. antihistamines $3.4 \%$, immunomodulators in $3.4 \%$, nasal decongestants in $24.1 \%$. Finally, $10.8 \%$ of the parents reported starting antibiotics in case of fever without doctor's prescription.

\section{Conclusion}

The gaps in parental knowledge of the management of ARI were identified. Further interventions are needed to improve parents' attitudes during their children's ARI.

Medication Usage In Case Of ARI In Children Without Doctor's Prescription
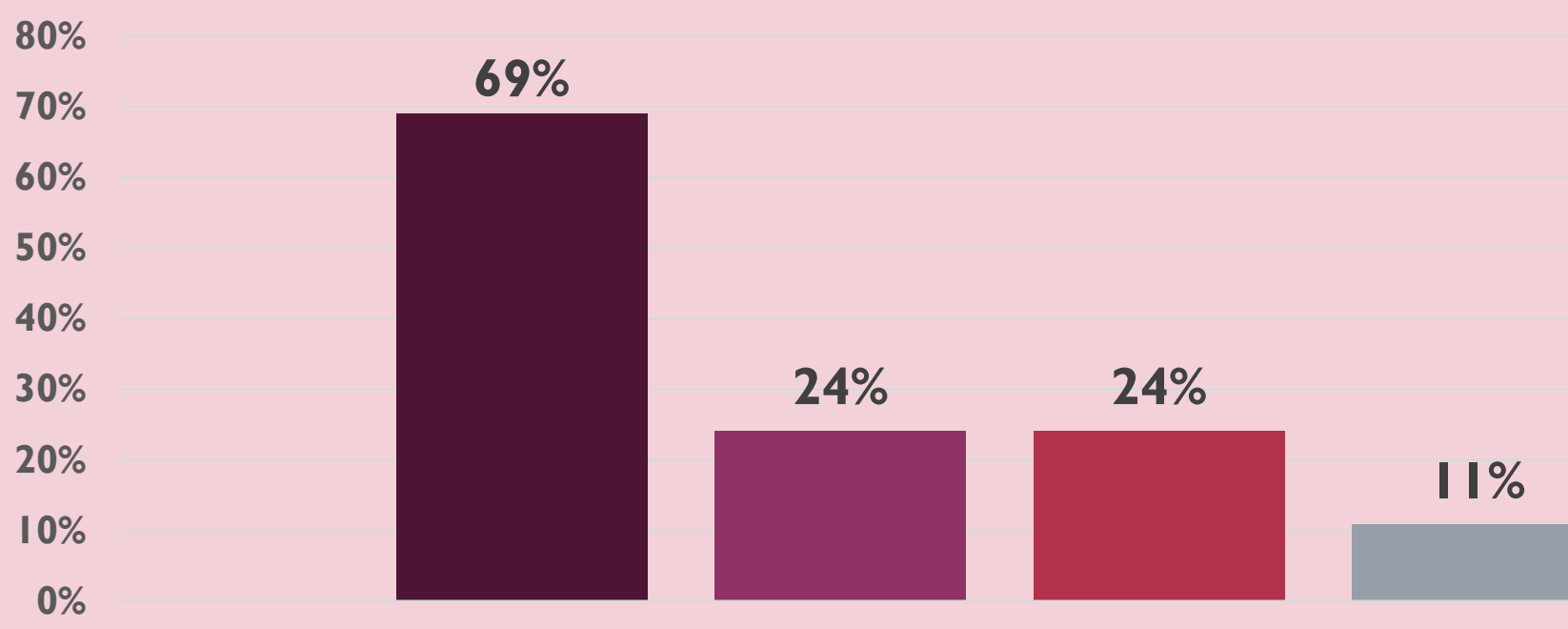

$3 \%$

- Antitussives

- Immunomodulators Antihistamines 